\title{
Hemodialysis improves endothelial venous function in end-stage renal disease
}

\author{
A.M.V. Silva1,2, L.U. Signori ${ }^{3}$, R.D.M. Plentz ${ }^{3}$, H. Moreno Jr. ${ }^{4}$, E. Barros ${ }^{1}$, \\ A. Belló-Klein ${ }^{1}$, B.D. Schaan ${ }^{3}$ and M.C. Irigoyen ${ }^{1,5}$ \\ ${ }^{1}$ Departamento de Fisiologia e Hospital de Clínicas de Porto Alegre, Universidade Federal do Rio Grande \\ do Sul, Porto Alegre, RS, Brasil \\ 2Departamento de Educação Física e Saúde, Universidade de Santa Cruz do Sul, Santa Cruz do Sul, \\ RS, Brasil \\ ${ }^{3}$ Laboratório de Investigação Clínica, Instituto de Cardiologia do Rio Grande do Sul, Porto Alegre, \\ RS, Brasil \\ ${ }^{4}$ Departamento de Farmacologia Cardiovascular, Universidade Estadual de Campinas, Campinas, \\ SP, Brasil \\ 5Unidade de Hipertensão, Instituto do Coração, Faculdade de Medicina, Universidade de São Paulo, \\ São Paulo, SP, Brasil \\ Correspondence to: B.D. Schaan, Unidade de Pesquisa, Instituto de Cardiologia do Rio Grande do Sul, \\ Avenida Princesa Isabel, 370, Santana, 90620-001 Porto Alegre, RS, Brasil \\ Fax: +55-51-3219-2802. E-mail: beatrizschaan@gmail.com
}

\begin{abstract}
The objective of the present study was to determine the acute effect of hemodialysis on endothelial venous function and oxidative stress. We studied 9 patients with end-stage renal disease (ESRD), $36.8 \pm 3.0$ years old, arterial pressure 133.8 $\pm 6.8 / 80.0 \pm 5.0$ $\mathrm{mmHg}$, time on dialysis $55.0 \pm 16.6$ months, immediately before and after a hemodialysis session, and 10 healthy controls matched for age and gender. Endothelial function was assessed by the dorsal hand vein technique using graded local infusion of acetylcholine (endothelium-dependent venodilation, EDV) and sodium nitroprusside (endothelium-independent venodilation). Oxidative stress was evaluated by measuring protein oxidative damage (carbonyls) and antioxidant defense (total radical trapping antioxidant potential - TRAP) in blood samples. All patients were receiving recombinant human erythropoietin for at least 3 months and were not taking nitrates or $\alpha$-receptor antagonists. EDV was significantly lower in ESRD patients before hemodialysis $(65.6 \pm 10.5)$ vs controls $(109.6 \pm 10.8 ; P=0.010)$ and after hemodialysis $(106.6 \pm 15.7 ; P=0.045)$. Endotheliumindependent venodilation was similar in all comparisons performed. The hemodialysis session significantly decreased TRAP $(402.0 \pm 53.5$ vs $157.1 \pm 28.3 \mathrm{U}$ Trolox/ $\mu \mathrm{L}$ plasma; $\mathrm{P}=0.001)$. There was no difference in protein damage comparing $\mathrm{ESRD}$ patients before and after hemodialysis. The magnitude of change in the EDV was correlated negatively with the magnitude of change in TRAP $(r=-0.70 ; P=0.037)$. These results suggest that a hemodialysis session improves endothelial venous function, in association with an antioxidant effect.
\end{abstract}

Key words: End-stage renal disease; Hemodialysis; Oxidative stress; Vascular endothelium

Research supported by CAPES, CNPq and FIPE/HCPA. Publication supported by Universidade Federal do Rio Grande do Sul and FAPESP.

Received September 3, 2007. Accepted May 17, 2008

\section{Introduction}

Patients with end-stage renal disease (ESRD) experience excess morbidity and mortality due to cardiovascular disease (CVD). These patients usually have several clas- sic CVD risk factors, but this does not fully explain the excessive CVD mortality (1). Among the emerging CVD risk factors, endothelial dysfunction and oxidative stress are currently emphasized, not only because they could explain the high incidence of CVD events in the ESRD 
population compared with the general population (2), but also because they may be new targets for therapeutic interventions.

Impaired endothelium-dependent vasodilation is extensively described in patients with ESRD undergoing renal replacement therapy by hemodialysis (3-5), a defect that may predispose them to accelerated atherosclerosis, as described for non-uremic patients with decreased endothelium-mediated vasodilation and coronary artery disease (6). Renal replacement therapy by kidney transplantation improves endothelial function (7), but reports of results obtained after hemodialysis are contradictory, some reporting improvement $(3,8,9)$, others not $(10,11)$, and yet another one showing increased endothelial dysfunction after a single session of hemodialysis (12).

Patients with ESRD have increased levels of oxidative stress markers and impaired endothelial cell function (13). Both reduced antioxidant systems and increased pro-oxidant activity generate the increased oxidative stress observed in ESRD patients (1). Even a single hemodialysis session can increase plasma levels of oxidized LDL (12) and decrease total antioxidant capacity (14). Thus, hemodialysis would indeed induce oxidative stress and impair the bioactivity of nitric oxide (NO). However, several studies have demonstrated that endogenous inhibitors of NO synthase accumulate in ESRD $(8,15)$ and are cleared by dialysis (8). Therefore, hemodialysis should be beneficial to endothelial function in view of its ability to clear dialysable endothelial toxins, but its known effect of causing high levels of oxidative stress could interfere with this effect.

All but one study cited above evaluated arterial endothelial function. The capacitance vessels are important in circulatory homeostasis. Indeed, the endotheliums of arteries and veins have different biological activities probably due to marked regional and segmental heterogeneity in vascular endothelial function (16). During hemodialysis, a large amount of fluid is removed from the body, thus the capacitance venous system would be expected to be influenced more than the arterial system. The aim of the present study was to determine endothelium-dependent and -independent venous function in patients with ESRD using the dorsal hand vein technique and by measuring oxidative stress before and after a single hemodialysis session.

\section{Material and Methods}

This study was performed on 9 patients ( 6 women and 3 men) with established ESRD (estimated glomerular filtration rate $<15 \mathrm{~mL} / \mathrm{min}$ ), who had been maintained on renal replacement therapy with hemodialysis for at least three months at the Nephrology Unit of Hospital de Clínicas de Porto Alegre. Hemodialysis was performed three times a week ( $4 \mathrm{~h} /$ session). All patients were receiving recombinant human erythropoietin (3000-6000 U/week) for at least 3 months. Four patients were taking angiotensin-converting enzyme (ACE) inhibitors, two patients were taking ACE inhibitors plus diuretics, two patients were taking ACE inhibitors plus calcium channel blockers, and one patient was taking an ACE inhibitor plus an antiplatelet agent. The patients were not given nitrates or $\alpha$-receptor antagonists. All medications were discontinued $12 \mathrm{~h}$ before the evaluation. During the period of the study, all patients continued the usual dialysis prescribed using Fresenius Medical Care 4008 B dialysis machines with polysulfone membranes (Fresenius Medical Care, GE). All patients were dialyzed against bicarbonate. Ten age- and sex-matched healthy control subjects ( 6 women, 4 men) not using any medication were also recruited. The study was previously approved by the local research Ethics Committee (process 02-413/2002) and all subjects gave a written informed consent.

Exclusion criteria included diabetes, age $>60$ years, smoking, obesity (body mass index $>30 \mathrm{~kg} / \mathrm{m}^{2}$ ) and patients who had hypotensive episodes during hemodialysis (more than $20 \mathrm{mmHg}$ mean arterial pressure reduction). No patient had symptomatic coronary artery disease or cerebrovascular disease. The etiology of ESRD was as follows: systemic arterial hypertension $(N=2)$, polycystic kidney disease $(N=2)$, reflux nephropathy $(N=2)$, focal segmental glomerulosclerosis $(N=1)$, Henoch-Shoenlein purpura $(\mathrm{N}=1)$, and unknown $(\mathrm{N}=1)$. All subjects avoided caffeine and alcohol-containing drinks on the day of the study and were fasted for at least $4 \mathrm{~h}$ before each evaluation. They were given sodium heparin as a bolus dose of $5000 \mathrm{U}$ at the beginning of dialysis, followed by $1000 \mathrm{U} / \mathrm{h}$.

\section{Dorsal hand vein technique}

Venous endothelial function was assessed in all patients and controls with the dorsal hand vein technique immediately before and after hemodialysis with the same hand vein on the non-fistula arm or the non-dominant arm in controls. The dorsal hand vein technique used was described by Aellig (17), and has been used by our group (18). Briefly, a 23-gauge butterfly needle was inserted into a suitable vein on the back of the hand with the arm positioned at an upward angle of 30 degrees and a continuous infusion of $0.9 \%$ saline $(0.3 \mathrm{~mL} / \mathrm{min})$ was started. A tripod holding a linear variable differential transformer (LVDT; Shaevitz Engineering, Pennsauken, NJ, USA) was mounted on the hand with the central aperture of the LVDT that contained a movable metallic core at a distance of 10 
$\mathrm{mm}$ downstream from the tip of the needle. The signal output of the LVDT, which is linearly proportional to the vertical movement of the core, provided a measurement of the vein diameter. Readings were taken at a congestive pressure of $40 \mathrm{mmHg}$ by inflating a blood pressure cuff placed on the upper portion of the arm being studied. Results are reported as normalized dose-response curves in which the diameter of the vein during saline infusion with the cuff inflated was taken to be $100 \%$ relaxation.

The vein was preconstricted by infusing increasing doses of the $\alpha 1$-adrenergic selective agonist phenylephrine (25 to $8333.3 \mathrm{ng} / \mathrm{min}$ ) until the dose that produced approximately $70 \%$ constriction of the vein was identified $\left(E D_{70}\right)$. This degree of preconstriction was taken to be $0 \%$ venodilation. The endothelium-dependent venodilation was assessed with incremental infusions of acetylcholine (ACh; 3.6, 36, 360, 720, $1800 \mathrm{ng} / \mathrm{min}$ ), and endothelium-independent venodilation with sodium nitroprusside (SNP; 495.3 and $990.6 \mathrm{ng} / \mathrm{min}$ ) was calculated to be the percent of the range between 100 and $0 \%$ vasodilation. Drugs were infused with a Harvard infusion pump (Harvard Apparatus Inc., South Natick, MA, USA). Blood pressure and heart rate were monitored in the right leg with a sphygmomanometer. Ambient temperature was maintained between 21 and $24^{\circ} \mathrm{C}$.

\section{Oxidative stress}

Oxidative stress was measured in the ESRD patients and evaluated by measuring oxidative damage (protein oxidation) and antioxidant defense (total radical trapping antioxidant potential - TRAP). Blood samples were obtained pre- and post-hemodialysis (pre-HD and post-HD), centrifuged for $10 \mathrm{~min}$ at $1000 \mathrm{~g}$ (Sorval RC 5b-rotor SM 24, Du Pont Instruments, Norwalk, CT, USA), and plasma was separated.

Plasma was used to determine protein oxidation by means of carbonyl group measurements. It was incubated with 2.4 dinitrophenylhydrazine $(10 \mathrm{mM})$ in a $0.8 \mathrm{~mL} 2.5 \mathrm{M}$ $\mathrm{HCl}$ for $1 \mathrm{~h}$ at ambient temperature in the dark. Samples were vortexed every $15 \mathrm{~min}$. Then, $1 \mathrm{~mL} 20 \%$ TCA (w/v) was added to a $0.2-\mathrm{mL}$ sample, left in ice for $10 \mathrm{~min}$ and centrifuged for $5 \mathrm{~min}$ at $1000 \mathrm{~g}$, to collect protein precipitates. Another wash was performed with $0.8 \mathrm{~mL}$ cold $10 \%$ TCA. The pellet was washed three times with ethanol:ethyl acetate $(1: 1)(\mathrm{v} / \mathrm{v})$. The final precipitates were dissolved in $6 \mathrm{M}$ guanidine hydrochloride, left for $10 \mathrm{~min}$ at $37^{\circ} \mathrm{C}$, and absorbance was read at $360 \mathrm{~nm}$ (19). The results are reported as $\mathrm{nmol} / \mathrm{mg}$ protein.

TRAP or antioxidant capacity, was measured by luminescence using 2,2'-azo-bis (2-amidinopropane), a source of alkyl peroxyl free radicals, and luminol. A calibration curve was obtained using 0.2 to $1 \mu \mathrm{M}$ Trolox (6-hydroxy2,5,7,8-tetramethylchroman-2-carboxylic acid). The addition of plasma samples instead of Trolox elicits an induction time related to the initial amount of sample added (20). Luminescence was measured with a scintillation counter in the out-of-coincidence mode and the results are reported as $\mathrm{mM}$ Trolox/mg protein.

\section{Other biochemical measurements}

Blood samples were obtained before and after dialysis for analysis of hematocrit, total cholesterol, triglycerides, and plasma glucose. Total cholesterol, triglycerides and plasma glucose were determined by automated enzymatic commercial kits (Roche, Mannheim, Germany).

\section{Statistical analysis}

Analyses were performed using SPSS ${ }^{\circledR}$ Base 13.0 (SPSS Inc., Chicago, IL, USA). Results are reported as means \pm SEM. Data for all patients were included in the calculations for all Tables and Figures. Variables that did not have a Gaussian distribution (Kolmogorov-Smirnov test) were log-transformed before analyses $\left(\log _{10}\right)$. Differences were analyzed using the Student paired or unpaired $t$-test as appropriate. The dose-percentage venodilation maximum response curves in each $\mathrm{ACh}$ dose were analyzed by two-way repeated measures ANOVA followed by the post hoc Bonferroni test. The magnitude of change $(\Delta)$ in the endothelium-dependent venodilation, TRAP and carbonyls was calculated as the difference between preand post-HD. The association between endothelial venous function and oxidative stress was calculated using Pearson's correlation. The differences were considered to be statistically significant when $\mathrm{P}<0.05$.

\section{Results}

Table 1 shows the clinical and laboratory characteristics of the patients and controls studied. No differences were observed between the control group and patients with ESRD concerning age and body mass index. There were significant differences in hematocrit between pre-HD and controls $(P<0.001)$, pre-HD vs post-HD $(P=0.012)$, and in body weight from pre-HD to post-HD evaluation ( $P$ $<0.001)$. There were no differences between controls $v s$ pre-HD and between pre-HD vs post-HD in terms of total cholesterol, triglycerides, plasma glucose, systolic arterial pressure, diastolic arterial pressure, and mean arterial pressure. The mean time since the beginning of hemodialysis was $55.0 \pm 16.6$ months.

Endothelial venous function data are shown in Table 2. Maximum venodilation by ACh was significantly improved 
Table 1. Clinical and laboratory characteristics of patients with end-stage renal disease before (pre-HD) and after hemodialysis (post-HD) and controls.

\begin{tabular}{lrcc}
\hline Parameter & $\begin{array}{r}\text { Control } \\
(\mathrm{N}=10)\end{array}$ & $\begin{array}{c}\text { Pre-HD } \\
(\mathrm{N}=9)\end{array}$ & $\begin{array}{c}\text { Post-HD } \\
(\mathrm{N}=9)\end{array}$ \\
\hline Hematocrit $(\%)$ & $41.8 \pm 1.3$ & $31.6 \pm 1.6^{*}$ & $35.5 \pm 1.9^{+}$ \\
Total cholesterol $(\mathrm{mg} / \mathrm{dL})$ & $181.9 \pm 8.9$ & $160.3 \pm 12.8$ & $161.6 \pm 13.0$ \\
Triglycerides $(\mathrm{mg} / \mathrm{dL})$ & $66.8 \pm 5.9$ & $78.1 \pm 7.5$ & $78.8 \pm 5.6$ \\
Plasma glucose $(\mathrm{mg} / \mathrm{dL})$ & $87.6 \pm 1.8$ & $90.5 \pm 1.3$ & $92.4 \pm 2.4$ \\
Body weight $(\mathrm{kg})$ & $66.1 \pm 3.4$ & $60.2 \pm 4.0$ & $57.6 \pm 3.9^{+}$ \\
Systolic arterial pressure $(\mathrm{mmHg})$ & $118.0 \pm 3.4$ & $133.8 \pm 6.8$ & $127.5 \pm 4.1$ \\
Diastolic arterial pressure $(\mathrm{mmHg})$ & $74.3 \pm 2.6$ & $80.0 \pm 5.0$ & $80.0 \pm 3.3$ \\
Mean arterial pressure $(\mathrm{mmHg})$ & $88.9 \pm 2.8$ & $97.9 \pm 5.0$ & $95.8 \pm 3.0$
\end{tabular}

Data are reported as means \pm SEM for all subjects.

${ }^{*} \mathrm{P}<0.05$ vs controls (Student unpaired $t$-test); ${ }^{+} \mathrm{P}<0.05$ vs pre-HD (Student paired $t$-test).

Table 2. Endothelial venous function of patients with end-stage renal disease before (pre-HD) and after hemodialysis (post-HD) and controls.

\begin{tabular}{lccc}
\hline Response & $\begin{array}{c}\text { Control } \\
(\mathrm{N}=10)\end{array}$ & $\begin{array}{c}\text { Pre-HD } \\
(\mathrm{N}=9)\end{array}$ & $\begin{array}{c}\text { Post-HD } \\
(\mathrm{N}=9)\end{array}$ \\
\hline Venoconstriction (\%, phenyl) & $77.0 \pm 2.9$ & $78.8 \pm 3.9$ & $78.1 \pm 4.2$ \\
$\mathrm{E}_{\max }(\%$, acetylcholine) & $109.6 \pm 10.8$ & $65.6 \pm 10.5^{*}$ & $106.6 \pm 15.7^{+}$ \\
$\mathrm{E}_{\max }(\%, \mathrm{SNP})$ & $147.7 \pm 13.1$ & $150.3 \pm 13.7$ & $157.2 \pm 16.3$ \\
Drug infusion concentrations & & & \\
$\mathrm{ED}_{70}$ (ng/min, phenyl) & $38.9 \pm 10.1$ & $61.1 \pm 20.8$ & $65.3 \pm 21.6$ \\
$\mathrm{E}_{\max }$ (ng/min, acetylcholine) & $964.0 \pm 222.4$ & $892.0 \pm 290.2$ & $865.1 \pm 277.9$ \\
$\mathrm{E}_{\max }$ (ng/min, SNP) & $594.4 \pm 66.0$ & $550.3 \pm 55.0$ & $605.4 \pm 72.8$ \\
\hline
\end{tabular}

Data are reported as means \pm SEM for all subjects. Phenyl = phenylephrine; $\mathrm{SNP}=$ sodium nitroprusside; $\mathrm{E}_{\max }=$ maximum effect $; \mathrm{ED}_{70}=$ dose that produced approximately $70 \%$ constriction of the vein. Drug infusion concentrations are reported before $\log _{10}$ transformation.

${ }^{*} \mathrm{P}<0.05$ vs controls (Student unpaired $t$-test) ${ }^{+} \mathrm{P}<0.05$ vs pre-HD (Student paired $t$-test). after a single hemodialysis session $(P=0.045)$. Endothelium-dependent venodilation was significantly lower in pre-HD patients compared with controls $(P=0.010)$. Dilation in response to SNP (endothelium-independent venodilation) was similar pre- and post-HD, or when compared to controls.

Figure 1 presents the ACh vs venodilation dose-response curve. The doses of pre- and post-HD response curves were similar and the magnitude of the response was increased by hemodialysis $(P<0.001)$.

The dose of phenylephrine to reach $E D_{70}$ and doses of ACh and SNP needed to reach maximum venodilation were not different between controls and pre-HD patients or pre-HD vs post-HD measurements (Table 2). There were no significant differences in the diameter of baseline venodilation between controls (1.0 $\pm 0.1 \mathrm{~mm})$ and pre-HD patients $(0.9 \pm 0.1 \mathrm{~mm})$ and in pre-HD patients $(0.9 \pm 0.1 \mathrm{~mm})$ vs postHD patients $(1.1 \pm 0.2 \mathrm{~mm})$.

No protein oxidative damage was observed when pre-HD (15.8 $\pm 0.6 \mathrm{nmol} / \mathrm{mg}$ protein) $v s$ post-HD (16.6 $\pm 0.6 \mathrm{nmol} / \mathrm{mg}$ protein) were compared. However, there was a significant reduction of TRAP when pre-HD (402.0 \pm 53.5 $\mathrm{U}$ Trolox/ $\mu \mathrm{L}$ plasma) vs post-HD $(157.1 \pm 28.3$ $\mathrm{U}$ Trolox/ $\mathrm{L}$ plasma) were compared.

A negative correlation was detected between $\Delta$ of the endothelium-dependent venodilation and $\triangle$ of TRAP (Figure 2) when pre-HD and post-HD were compared. However, no correlation was demonstrable between $\Delta$ of endothelium-dependent venodilation and $\Delta$ of carbonyls.
Figure 1. Endothelial venous function of patients with end-stage renal disease before and after hemodialysis. The average maximal percentage venodilation is plotted against acetylcholine dose. Two-way repeated measures ANOVA was used for all comparisons between before (pre-HD; $N=9$ ) and after hemodialysis (post-HD; $\mathrm{N}=9$ ). ${ }^{*} \mathrm{P}<0.05$ vs pre-HD (post hoc Bonferroni test).

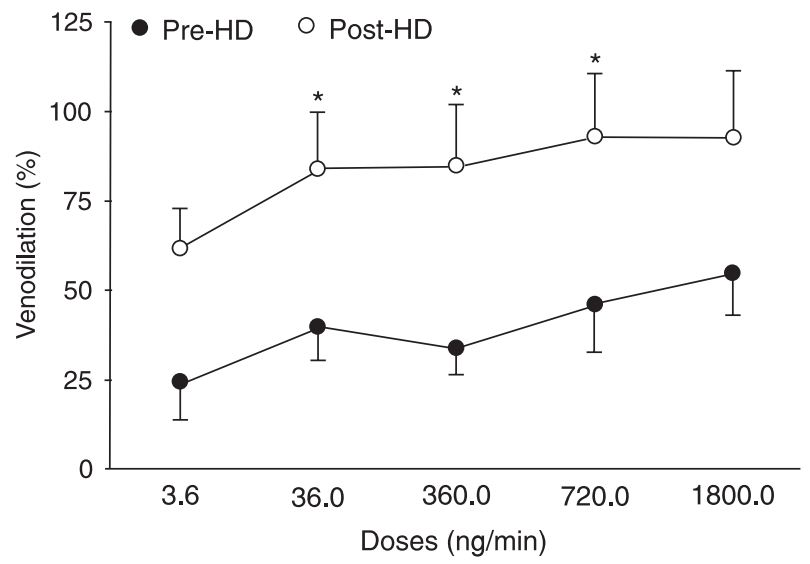




\section{Discussion}

The data presented here show that endothelium-dependent venodilation was impaired in patients with ESRD and that a single hemodialysis session can improve it significantly. Hemodialysis also reduced plasma TRAP and unmodified protein damage. Moreover, endotheliumdependent venodilation was correlated negatively with plasma TRAP.

The results of several studies (3-5) suggest that endothelial dysfunction is present in patients with ESRD submitted to maintenance hemodialysis. However, only the present study and the one reported by Hand et al. (3) in 1998 evaluated the endothelial venous function. Our data are in agreement with theirs in showing the presence of endothelial venous dysfunction - that is improved after a single hemodialysis session - and no impairment of endotheliumindependent vasodilation. The improvement of endothelial function has already been reported by others in the arterial bed $(8,9)$ and in the venous bed (3). However, in the present study, endothelial function was measured immediately before and immediately after hemodialysis, while in the study of Hand et al. (3), the pre-dialysis evaluation was performed $>24 \mathrm{~h}$ after the previous hemodialysis session and $<16 \mathrm{~h}$ before the next one. This is important, because the improvement of endothelial function persists for only 5 $\mathrm{h}$ after hemodialysis (8).

In other studies $(8,9)$, endothelial function was measured by flow-mediated dilatation of the brachial artery and forearm plethysmography, whereas we performed the endothelial evaluation using a pharmacological stimulus (ACh). We measured the vasodilation in the venous vascular bed, which seems to be advantageous, considering the close relationship between venous capacitance bed and hemodialysis-induced changes. Also, arterial wall changes induced by hypertension and atherosclerosis, both very

Figure 2. Plot of $\triangle$ TRAP (total radical trapping antioxidant potential) reduction and $\Delta$ venodilation induced by acetylcholine during the endothelial venous function determination. The Pearson correlation test was used to test the correlation for all 9 patients. common in these patients, could cause unexpected vasodilatory responses not actually representing endothelial dysfunction.

Our data, however, are different from those of Miyazaki et al. (12) who suggested that hemodialysis per se impairs endothelial function. We think that the venous bed is a more sensitive target of changes, so we could detect the improvement induced by the hemodialysis session because the dorsal hand vein is more sensitive to detect this improvement in this setting compared to flow-mediated vasodilation during reactive hyperemia using high-resolution ultrasound Doppler echocardiography. Even though we excluded patients who presented hypotension during the hemodialysis session, weight reduction was observed, because fluid was effectively removed by the procedure. This fact could be responsible for improved venous compliance and consequently, better endothelium-dependent venodilation after the hemodialysis session.

Improvement in endothelial venous function could be explained by other factors not studied by us. Asymmetric dimethylarginine (ADMA, an endogenous inhibitor of NO synthase), total plasma homocysteine (which directly damages the endothelium and may inactivate NO) $(8,21)$ and ADMA/L-arginine ratio fell significantly after hemodialysis, but there was no correlation between the plasma concentrations of these substances and flow-mediated dilation (8). However, another study showed that ADMA and symmetric dimethylarginine were poorly eliminated during hemodialysis. This is probably due to a high level of binding of both molecules to plasma proteins (22). Be that as it may, the concentrations of both dimethylarginines are increased in patients with ESRD and may explain at least in part endothelial dysfunction in this patient population.

Our results also present a reduction of TRAP induced by hemodialysis, which was not accompanied by protein oxidative damage. We did not evaluate other markers of

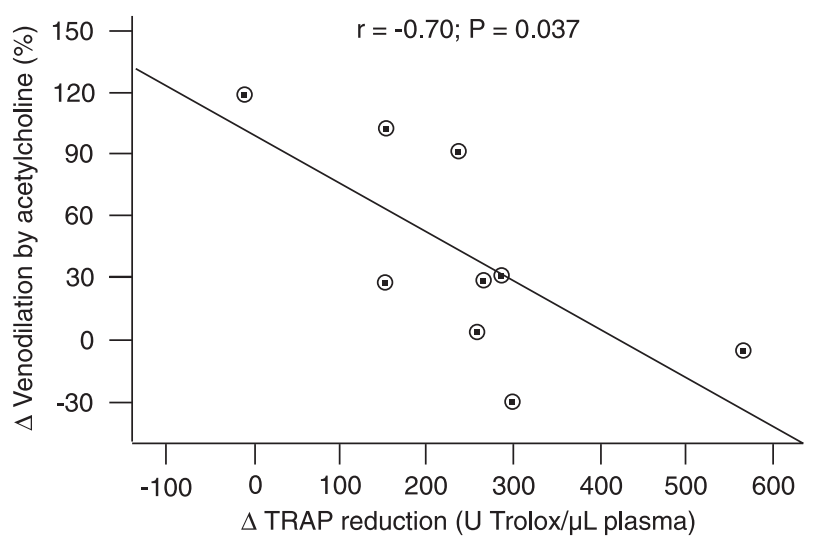


oxidative damage and antioxidant defense; therefore, we could not effectively prove that oxidative stress did not occur. However, increased endothelium-dependent vasodilation and reduced TRAP occurred after hemodialysis and were correlated negatively. These changes might mean that antioxidant defenses are effectively related to endothelial venous function improvement induced by dialysis, because patients with major improvement in endothelial function presented the lower TRAP reduction. Oxidative stress was measured through a very sensitive method that involves chemiluminescence, allowing high precision determinations with small amounts of sample (23). One limitation of our study was that we did not measure systemic inflammatory mediators that could be related to chronic renal failure itself and also to the hemodialysis session (24), since changes in these mediators could partially explain the endothelial function improvement.

Our results are different from those of Miyazaki et al. (12), who demonstrated that hemodialysis impairs endothelial function via oxidative stress, but their results could be related to the different plasma markers they used (oxidative damage and TRAP vs oxidized LDL). However, endothelial dysfunction is not related to LDL oxidation, suggesting that LDL oxidation might not be a major cause of vascular endothelial dysfunction in ESRD (25). Considering the present data, antioxidant treatments could be useful to improve the endothelial venous function of patients submitted to hemodialysis. Previous studies showed that a vitamin E-coated dialyzer may decrease oxidative

\section{References}

1. Locatelli F, Canaud B, Eckardt KU, Stenvinkel P, Wanner C, Zoccali C. Oxidative stress in end-stage renal disease: an emerging threat to patient outcome. Nephrol Dial Transplant 2003; 18: 1272-1280.

2. Zoccali C. Cardiovascular risk in uraemic patients - is it fully explained by classical risk factors? Nephrol Dial Transplant 2000; 15: 454-457.

3. Hand MF, Haynes WG, Webb DJ. Hemodialysis and Larginine, but not $\mathrm{D}$-arginine, correct renal failure-associated endothelial dysfunction. Kidney Int 1998; 53: 1068-1077.

4. Nakanishi T, Ishigami Y, Otaki Y, Izumi M, Hiraoka K, Inoue $\mathrm{T}$, et al. Impairment of vascular responses to reactive hyperemia and nitric oxide in chronic renal failure. Nephron 2002; 92: 529-535.

5. Kocak H, Ceken K, Dinckan A, Mahsereci E, Yavuz A, Yucetin L, et al. Assessment and comparison of endothelial function between dialysis and kidney transplant patients. Transplant Proc 2006; 38: 416-418.

6. Heitzer T, Schlinzig T, Krohn K, Meinertz T, Munzel T. Endothelial dysfunction, oxidative stress, and risk of cardio- stress $(12,26)$, and oral vitamin E can reduce cardiovascular events in patients on hemodialysis (27). These studies further support the role of oxidative stress and its treatment in the development and prevention of cardiovascular complications in these patients.

It is well-known that endothelium-dependent vasodilation is positively correlated with total antioxidative activity, reduced glutathione (GSH), and lag phase of LDL and negatively correlated with oxidized GSH (GSSG), GSSG/ GSH and diene conjugates, showing that an impaired endothelium vasodilation function and oxidative stress are related to each other in patients with ESRD (13). A recent study showed that flow-mediated dilation, oxidative stress, and ADMA levels are associated with ESRD. Additionally, levels of oxidative stress markers and ADMA independently determine endothelial function (28).

The present findings allow us to conclude that a single session of hemodialysis improved endothelial venous function and that antioxidant potential might be associated with this improvement in patients with ESRD. The evaluation of venous and arterial endothelial function in these patients, before and after a hemodialysis session, can provide better understanding of the difference of responses observed between the different vascular beds. Just as patients with ESRD present endothelial dysfunction for multifactorial reasons, changes in endothelial function resulting from a hemodialysis session must also be attributed to a combination of factors that have not yet been fully identified. vascular events in patients with coronary artery disease. Circulation 2001; 104: 2673-2678.

7. Passauer J, Bussemaker E, Lassig G, Gross P. Kidney transplantation improves endothelium-dependent vasodilation in patients with endstage renal disease. Transplantation 2003; 75: 1907-1910.

8. Cross JM, Donald A, Vallance PJ, Deanfield JE, Woolfson RG, MacAllister RJ. Dialysis improves endothelial function in humans. Nephrol Dial Transplant 2001; 16: 1823-1829.

9. McGregor DO, Buttimore AL, Lynn KL, Yandle T, Nicholls MG. Effects of long and short hemodialysis on endothelial function: a short-term study. Kidney Int 2003; 63: 709-715.

10. Migliacci R, Falcinelli F, Imperiali P, Floridi A, Nenci GG, Gresele P. Endothelial dysfunction in patients with kidney failure and vascular risk factors: acute effects of hemodialysis. Ital Heart J 2004; 5: 371-377.

11. Kosch M, Levers A, Barenbrock M, Matzkies F, Schaefer $\mathrm{RM}$, Kisters $\mathrm{K}$, et al. Acute effects of haemodialysis on endothelial function and large artery elasticity. Nephrol Dial Transplant 2001; 16: 1663-1668. 
12. Miyazaki $\mathrm{H}$, Matsuoka $\mathrm{H}$, Itabe $\mathrm{H}$, Usui $\mathrm{M}$, Ueda $\mathrm{S}$, Okuda $\mathrm{S}$, et al. Hemodialysis impairs endothelial function via oxidative stress: effects of vitamin E-coated dialyzer. Circulation 2000; 101: 1002-1006.

13. Annuk M, Zilmer M, Lind L, Linde T, Fellstrom B. Oxidative stress and endothelial function in chronic renal failure. J Am Soc Nephrol 2001; 12: 2747-2752.

14. Jackson $P$, Loughrey $C M$, Lightbody $\mathrm{JH}$, McNamee $\mathrm{PT}$, Young IS. Effect of hemodialysis on total antioxidant capacity and serum antioxidants in patients with chronic renal failure. Clin Chem 1995; 41: 1135-1138.

15. Busch M, Fleck C, Wolf G, Stein G. Asymmetrical (ADMA) and symmetrical dimethylarginine (SDMA) as potential risk factors for cardiovascular and renal outcome in chronic kidney disease - possible candidates for paradoxical epidemiology? Amino Acids 2006; 30: 225-232.

16. de Sousa MG, Yugar-Toledo JC, Rubira M, Ferreira-Melo SE, Plentz R, Barbieri D, et al. Ascorbic acid improves impaired venous and arterial endothelium-dependent dilation in smokers. Acta Pharmacol Sin 2005; 26: 447-452.

17. Aellig $W H$. A new technique for recording compliance of human hand veins. Br J Clin Pharmacol 1981; 11: 237-243.

18. Signori LU, Vargas da Silva AM, Della Mea Plentz R, Geloneze B, Moreno H Jr, Bello-Klein A, et al. Reduced venous endothelial responsiveness after oral lipid overload in healthy volunteers. Metabolism 2008; 57: 103-109.

19. Reznick AZ, Packer L. Oxidative damage to proteins: spectrophotometric method for carbonyl assay. Methods Enzymol 1994; 233: 357-363.

20. Lissi E, Pascual C, Del Castillo MD. Luminol luminescence induced by 2,2 '-azo-bis(2-amidinopropane) thermolysis. Free Radic Res Commun 1992; 17: 299-311.
21. Hewitson CL, Whiting MJ, Barbara JA, Mangoni AA. Acute effects of haemodialysis on biochemical modulators of endothelial function. $J$ Intern Med 2007; 262: 571-580.

22. Boger RH, Zoccali C. ADMA: a novel risk factor that explains excess cardiovascular event rate in patients with end-stage renal disease. Atheroscler Suppl 2003; 4: 23-28.

23. Gutierrez LL, Mazzotti NG, Araujo AS, Klipel RB, Fernandes TR, Llesuy SF, et al. Peripheral markers of oxidative stress in chronic mercuric chloride intoxication. Braz J Med Biol Res 2006; 39: 767-772.

24. Poyrazoglu OK, Dogukan A, Yalniz M, Seckin D, Gunal AL. Acute effect of standard heparin versus low molecular weight heparin on oxidative stress and inflammation in hemodialysis patients. Ren Fail 2006; 28: 723-727.

25. Bolton CH, Downs LG, Victory JG, Dwight JF, Tomson CR, Mackness MI, et al. Endothelial dysfunction in chronic renal failure: roles of lipoprotein oxidation and pro-inflammatory cytokines. Nephrol Dial Transplant 2001; 16: 1189-1197.

26. Morimoto H, Nakao K, Fukuoka K, Sarai A, Yano A, Kihara $\mathrm{T}$, et al. Long-term use of vitamin E-coated polysulfone membrane reduces oxidative stress markers in haemodialysis patients. Nephrol Dial Transplant 2005; 20: 27752782.

27. Boaz M, Smetana S, Weinstein T, Matas Z, Gafter U, laina $A$, et al. Secondary prevention with antioxidants of cardiovascular disease in endstage renal disease (SPACE): randomised placebo-controlled trial. Lancet 2000; 356: 1213-1218.

28. Yilmaz MI, Saglam M, Caglar K, Cakir E, Sonmez A, Ozgurtas T, et al. The determinants of endothelial dysfunction in CKD: oxidative stress and asymmetric dimethylarginine. Am J Kidney Dis 2006; 47: 42-50. 